\title{
DEMOCRACIA E DIREITOS HUMANOS COMO IDEOLOGIA: AS CRÍTICAS DE JÜRGEN HABERMAS À POLÍTICA DE PODER UNILATERAL NORTEAMERICANA E À ONU
}

\author{
[ DEMOCRACY AND HUMAN RIGHTS AS IDEOLOGY: JÜRGEN HABERMAS CRITICISM TO THE \\ NORTH AMERICAN UNILATERAL POWER POLICY AND TO THE UNITED NATIONS ]
}

\author{
Jorge Adriano Lubenow * \\ Universidade Federal da Paraíba, Brasil
}

\begin{abstract}
Resumo: O artigo está dividido em duas partes. A primeira trata da crítica de Habermas à concepção ética do projeto americano de moralização do direito internacional, de colocar o ethos no lugar do direito, à política externa unilateral e militar que ignora o direito, rejeita a Organização das Nações Unidas (ONU) e despreza pontos de vista normativos da democracia e dos direitos humanos, denunciados por Habermas como ideológicos, do quanto esta interpretação unilateral hegemônica do direito internacional está vinculada à razão neoliberal e seu modelo de sociedade mercantil mundial que visa substituir o mecanismo regulador da política pelo do mercado. Para Habermas, há um parentesco entre o programa neoliberal de produção de uma sociedade do direito privado em escala mundial e as estruturas econômicas globais existentes, e que isso não passa de um projeto de sociedade exportado pelo governo americano a partir de uma teoria da modernização interpretada pelo Consenso de Washington e pela Escola de Chicago que visa subtrair os processos sociais básicos do controle político pelo controle econômico. Em contrapartida, uma ordem unipolar hegemônica, uma justificação ética de um procedimento unilateral que invoca valores da sua própria cultura como supostamente universais, não seria recomendável por razões normativas, pois não garante discernir seus próprios interesses nacionais daqueles que
\end{abstract}

ABSTRACT: The article is divided into two parts. The first deals with Habermas critique to the ethical conception of the American project of moralizing international law, to replacing ethos in place of law, to the unilateral and military foreign policy that ignores law, rejects the United Nations (UN) and disregards normative views of democracy and human rights, denounced as ideological, of how this hegemonic unilateral interpretation of international law is linked to neoliberal reason and its model of global mercantile society that aims to replace the regulatory mechanism of politics by the regulatory mechanism of the market. For Habermas, there is a relationship between the neoliberal program of production of a private law society on a world scale and the existing global economic structures, and that this is nothing more than a project of society exported by the American government from an interpreted theory of modernization by the Washington Consensus and by the Chicago School that seeks to subtract the basic social processes of political by economic control. On the other hand, a unipolar hegemonic order, an ethical justification of a unilateral procedure that invokes values of its own culture as supposedly universal, would not be recommended for normative reasons, because it fails to guarantee that it discerns its own national interests from those that could be generalized and shared with others countries.

* Doutor em Filosofia pela UNICAMP. Pós-doutor em Filosofia pela Europa-Universität Flensburg/Alemanha e pelo CNPq/FAPEPI/UFPI. Professor Adjunto IV do DFE do Programa de Pós-graduação em Filosofia da Universidade Federal da Paraíba (UFPB). É coordenador do Centro de Pesquisas em Democracia da UFPB (www.ufpb.br/cepede) e do Grupo de Pesquisa em Democracia(CNPq/UFPB).m@ilto:jlubenow@hotmail.com 
poderiam ser generalizados e comungados com outros países. A segunda parte trata das críticas, reformas e desafios da ONU. Embora algumas inovações do direito internacional tenham fortalecido o peso político da ONU, seria indispensável uma reforma na estrutura institucional para uma maior eficiência no sentido de uma constituição política de uma sociedade mundial, e que seja capaz de, não apenas orientar, mas também implementar institucionalmente os elementos normativos da democracia e dos direitos humanos. A não incorporação institucional é um dos principais limites para o aprofundamento democrático das instituições transnacionais existentes.

Palavras-chave: Jürgen Habermas; Democracia transnacional; Direitos humanos; Direito imperial; Ideologia; ONU
The second part deals with the criticisms, reforms and challenges of the UN. Although some innovations in international law have strengthened the political weight of the UN, a reform of the institutional structure for greater efficiency towards a political constitution of a world society is indispensable, and that has the capacity, not only to guide, but also to institutionally implement the normative elements of democracy and human rights. The non-institutional incorporation is one of the main limits for the democratic deepening of existing transnational institutions.

KeYworDS: Jürgen Habermas; Transnational democracy; Human Rights; Imperial law; Ideology; UN

$\mathrm{E}$ sta primeira parte trata das críticas de Habermas à política de poder unilateral norte-americana, o comportamento imperialista que ignora o direito internacional substituindo-o pelo direito nacional/imperial, despreza acordos internacionais e princípios normativos da democracia e dos direitos humanos. Os norteamericanos defenderiam uma concepção de direito internacional imperial, que se distingue do constitucionalismo kantiano, reforçando o unilateralismo hegemônico através do uso da chantagem econômica e da força militar.

\section{a) Críticas ao unilateralismo hegemônico}

Na obra Era das transições [Suhrkamp, 2001], no capítulo 2, diante da política do poder norte-americano, Habermas argumenta pela defesa de um pacifismo apoiado no direito. "Torna-se atual a ideia de uma transformação do direito internacional num direito dos cidadãos do mundo"1. Defende uma transição do clássico direito das nações para o direito cosmopolita de uma sociedade civil de cidadãos do mundo, cujo caminho teria sido aberto pela criação da ONU. Nesse sentido, trata-se na necessidade de institucionalização de procedimentos de solução de conflitos e uma juridificação abrangente das relações internacionais. Esta visão mais constitucional do direito internacional contrapõe-se àquela visão norte-americana de direito imperial.

Posteriormente, no prefácio da obra $O$ Ocidente dividido [Suhrkamp, 2004] Habermas escreve:

Não foi a ameaça do terrorismo internacional que dividiu o Ocidente, mas a atual política do governo dos Estados Unidos, que ignora o direito internacional, joga para escanteio as Nações Unidas e assume o risco de um rompimento com a Europa $^{2}$.

No capítulo 2, encontramos exemplos da crítica ao unilateralismo hegemônico americano, como as intervenções militares dos Estados Unidos mesmo sem autorização do Conselho de Segurança da ONU (Guerra do Golfo, Guerra do Iraque...), mostrando que os Estados Unidos abandonaram o papel de uma potência garantidora do direito internacional, ao adotar procedimentos que violam o direito internacional. Repetidas vezes o governo americano declarou que agiria mesmo sem mandato do Conselho de 
Segurança. A superpotência se arrogaria o direito de agir unilateralmente com o objetivo de fortalecer a posição hegemônica. Para Habermas, o unilateralismo hegemônico é a "política mundial americana":

(Na Guerra do Iraque) Os Estados Unidos passaram a exercer, como um fiel depositário, o papel em que a ONU fracassou (...). A dimensão crucial reside na seguinte pergunta: é possível, e aceitável, a substituição de um contexto de justificação do direito internacional por uma política unilateral de ordenamento mundial de um agente hegemônico que atribui a si mesmo esse poder? ${ }^{3}$

Embora sejam os criadores da Organização das Nações Unidas (ONU) e precursores do poder civilizador do direito internacional, os Estados Unidos tornaramse um agente hegemônico alheio ao direito internacional, rejeitando e marginalizando as Nações Unidas e o direito internacional. Por isso a crítica ao belicismo americano no Iraque é lida como uma afronta a direito internacional. Escreve Habermas:

A violação desrespeitosa do direito internacional sinaliza a vontade da superpotência de intervir como bem entende em áreas de guerra. Quem ignora de tal forma o direito, exime os próprios interesses, valores e convicções morais da obrigatoriedade de justifícação mediante um procedimento apartidário, e dá a outras grandes potências a licença de violar na primeira oportunidade, de modo igualmente desrespeitoso, a proibição do uso da força ${ }^{4}$.

Entre nós, o unilateralismo dos Estados Unidos fortaleceu a visão de que a Europa precisa aprender a falar no mundo com uma voz .

No capítulo 7, numa entrevista sobre guerra e paz, Habermas critica a violação do direito internacional pelos Estados Unidos, o desprezo do governo americano pelo direito internacional e por acordos internacionais, o uso brutal da força militar, a política de mentira e chantagem:

Independente das mentiras insufladas nesse meio tempo pelo atual governo dos EUA, a última Guerra do Golfo foi uma violação evidente do direito internacional e foi anunciada, inclusive publicamente, por Bush perante as Nações Unidas, em setembro de 2002. Não havia nenhum dos dois fatos que poderiam ter justificado tal intervenção: seja uma resolução pertinente do Conselho de Segurança, ou uma agressão iminente por parte do Iraque. Isso vale independentemente de encontrarse ou não armas de destruição em massa no Iraque. Não existe justificativa posterior para um ataque preventivo: ninguém pode fazer guerra levado por suspeita ${ }^{6}$.

Apesar dos Estados Unidos terem ajudado com intervenção militar na vitória sobre o terror nazista; apesar do escudo nuclear dos Estados Unidos ter favorecido a construção e ampliação dos Estados de bem-estar europeus; apesar dos Estados Unidos terem tomado a iniciativa da fundação das Nações Unidas; apesar de desencadearem várias inovações do direito internacional, os EUA adotaram - mais especificamente nas Guerras do Golfo, do Iraque e na "guerra contra o terrorismo" - uma política externa unilateral, tornando-se um agente hegemônico alheio ao direito internacional, caracterizada pela marginalização ofensiva das Nações Unidas e o desprezo brutal do direito internacional ${ }^{7}$. Trata-se de uma ruptura jurídica radical provocada pelo governo Bush, que ignorou propositadamente premissas jurídicas válidas, e que obrigou o Conselho de Segurança da ONU a abençoar a política agressiva dos norte-americanos no Iraque ou recolher-se à sua insignificância. Segundo Habermas, trata-se de um etnocentrismo americano travestido de (falso) universalismo:

A questão controversa não foi se a justiça entre as nações é possível, mas através de que caminho (...). O comportamento do governo americano só permite a conclusão de que na sua visão o direito internacional se esgotou como meio para a resolução de conflitos, a realização da democracia e dos direitos humanos. A 
potência mundial transforma esses objetivos no conteúdo publicamente declarado de uma política que não invoca mais o direito, mas os próprios valores éticos e as próprias convicções morais: ela coloca as suas próprias justificativas morais no lugar dos procedimentos jurídicos prescritos. Mas um não pode substituir o outro (...). Mesmo uma potência altamente moderna como os EUA reincide no falso universalismo dos antigos impérios, quando em questões de justiça internacional substituem o direito positivo pela ética e moral. Na perspectiva de Bush "nossos" valores são valores universalmente válidos, que todas as outras nações devem aceitar pelo seu próprio bem. $\mathrm{O}$ falso universalismo é um etnocentrismo alargado ao geral $^{8}$.

Na obra Ach Europa [Suhrkamp, 2008], no capítulo 9, ${ }^{9}$ tendo como pano de fundo o neoconservadorismo e o realismo político (Machtpolitik), Habermas retoma o problema da unipolaridade norte-americana, da disputa pela hegemonia dos jogos de poder, do modo político norte-americano unilateral e militar de conseguir o equilíbrio político na sociedade mundial multicultural de resolver/estabilizar os riscos/elementos de instabilidade resultantes dos conflitos de interesses entre ocidente $\mathrm{x}$ oriente, judeus/cristãos x islâmicos, terrorrismo islâmico x militarismo americano, capitalismo x comunismo [para Habermas, o "equilíbrio unipolar" falhará por causa da complexidade multicultural da sociedade mundial], e de como os pontos de vista normativos da democracia e dos direitos humanos não passam de ideologia:

Esse tipo de gerenciamento de risco moldou a política do governo Bush e definiu um modo de política caracterizado pela preferência por estratégias unilaterais multilaterais de tomada de decisão, meios militares em vez de diplomáticos de resolução de conflitos assim como um cálculo de interesses em curtos em vez de longos horizontes de tempo. Os pontos de vista normativos justificativos avançados, como a exportação da democracia e a aplicação dos direitos humanos, tornaram-se, entretanto, uma mera ideologia. Claramente hoje a política do governo Bush já se move em direção a uma política de poder "realista"10.

Se, por um lado, no pós-guerra, os Estados Unidos desenvolveram um ativismo notável pelos direitos internacionais, pela liberação das relações comerciais e dos mercados financeiros, pelos acordos de não propagação de armas nucleares, entre outros, por outro lado, a recente política americana dos direitos internacionais não é um desdobramento daquele internacionalismo dos primeiros anos do pós-guerra. Os casos da recusa em reconhecer o Tribunal Penal Internacional, da entrada forçada unilateralmente no Iraque, da não-ratificação de acordos internacionais sobre controle de armas, dos direitos humanos e da proteção do meio ambiente, ignoram o direito internacional e solapam a reputação das Nações Unidas. Escreve Habermas:

Estes exemplos parecem se encaixar no modelo clássico de comportamento de um poder imperial que se esquiva de normas do direito internacional porque estas limitam o seu próprio espaço de ação (...). Na visão de uma superpotência que usa instrumentos do multilateralismo do direito internacional para a realização de seus próprios interesses, este desenvolvimento adquire um significado totalmente ambivalente. $\mathrm{O}$ que de um lado aparece como progresso em direção à constitucionalização do direito internacional, de outro, apresenta-se como realização bem-sucedida do direito imperial ${ }^{11}$.

Unilateralismo americano, substituição do direito internacional pelo direito nacional/imperial, também lida a partir da postura do então presidente Bush:

Este presidente (na época Bush) realiza de modo unilateral os interesses nacionais de ordenação espacial e de segurança em nome do ethos de uma nova ordem mundial liberal, porque reconhece nela a globalização do próprio ethos substituir o direito da comunidade internacional, tudo o que ainda se chamar de direito internacional será, por definição, direito imperial (...). Em seu discurso sobre a situação da nação de 28 de janeiro de 2003, declarou solenemente que se o 
Conselho de Segurança não aprovasse uma ação militar contra o Iraque, independentemente de como fosse justificada, ele se colocaria eventualmente acima da proibição do uso da força da Carta da ONU ["O curso dessa nação não depende de outros"]. Ambos os atos tomados conjuntamente são uma ruptura inaudita com uma tradição jurídica que até então não havia sido questionada por nenhum governo americano. São a expressão do desprezo por uma das maiores realizações civilizatórias da espécie humana. Os discursos e ações deste presidente não permitem nenhuma outra conclusão a não ser a de que ele gostaria de substituir a força civilizatória de procedimentos jurídicos universalistas pelo armamento de um ethos americano munido de pretensão de universalidade ${ }^{12}$.

Ainda assim, apesar das restrições e críticas aos Estados Unidos, o projeto de uma constitucionalização do direito internacional só lograria êxito, segundo Habermas, tendo os Estados Unidos como locomotiva desse movimento. Conforme capítulo 7 de $O$ Ocidente dividido:

Por um lado, é um feliz acaso da história que a única superpotência seja ao mesmo tempo a mais antiga democracia na terra e por isso.... tem uma afinidade intrínseca com a ideia kantiana de uma regulamentação jurídica das relações internacionais. Por outro lado, é do interesse dos EUA fazer com que a ONU tenha capacidade de ação antes que uma grande potência menos democrática ascenda à superpotência. Impérios vêm e vão ${ }^{13}$.

Argumento similar encontrado no capítulo 8:

Os Estados Unidos não precisam desenvolver capacidades de ação no plano da política mundial. A superpotência pode esquivar-se de obrigações do direito internacional sem precisar temer duras sanções. Por outro lado, sem o apoio, e mesmo a condução americana, o projeto de uma ordem cosmopolita deve fracassar. Os Estados Unidos precisam decidir se devem se ater às regras internacionais do jogo, ou ignorar e instrumentalizar o direito internacional para tomar as rédeas da situação ${ }^{14}$.

\section{b) Ética liberal da potência mundial $x$ constitucionalização do direito internacional}

A interpretação norte-americana do direito internacional revela uma disputa entre poder e direito, entre moralização e constitucionalização das relações jurídicas internacionais, entre ética liberal da superpotência mundial e constitucionalização do direito internacional. Trata-se da disputa entre duas concepções diferentes de direito internacional, o que forma o pano de fundo do que Habermas chamou de "a divisão do Ocidente" 15 . Na obra $O$ Ocidente dividido, a parte IV trata "do projeto kantiano e o ocidente dividido". No capítulo 8, Habermas pergunta sobre as chances de constitucionalização do direito internacional, e no capítulo 8.3, detalha melhor a controvérsia entre a constitucionalização e a instrumentalização do direito internacional. Como antítese ao projeto americano de eticização do direito internacional - ethos no lugar do direito, falso universalismo travestido de etnocentrismo - Habermas apresenta como alternativa o modelo kantiano de constitucionalização do direito internacional ${ }^{16}$. O projeto kantiano de uma ordem cosmopolita difere do unilateralismo hegemônico em relação ao caminho para alcançar os objetivos e à forma concreta de realização:

No que concerne ao caminho, o unilateralismo fundado eticamente não está mais atrelado aos procedimentos estabelecidos pelo direito internacional. E quanto à forma concreta da nova ordem mundial, o liberalismo hegemônico não visa uma sociedade mundial moldada pelo direito e constituída politicamente, mas uma ordem internacional de Estados liberais formalmente independentes (...). Segundo 
este design a paz é assegurada não pelo direito, mas pelo poder imperial, e a sociedade mundial é integrada não através da constituição política de uma comunidade de cidadãos do mundo, mas através de relações sistêmicas, e finalmente através de mercado. Não há nem razões empíricas nem normativas que corroborem essa visão ${ }^{17}$.

Apesar do unilateralismo hegemônico como variante imperial do direito internacional, este motivo não seria suficiente para romper as premissas do projeto kantiano de constitucionalização do direito internacional. Para Habermas, uma justiça entre as nações não pode ser alcançada pelo caminho de uma moralização, mas apenas por uma regulamentação jurídica constitucional das relações internacionais. $\mathrm{O}$ projeto liberal unilateral hegemônico como variante imperial do direito internacional não seria recomendado por seu déficit normativo.

O desenvolvimento que leva à invasão das tropas da coligação no Iraque cria uma situação ambígua, para a qual não existe paralelo na história do direito internacional. Por outro lado, a superpotência, que acredita poder impor a sua vontade se preciso militarmente, de acordo com a sua livre escolha, portanto, independentemente das resoluções do Conselho de Segurança, invoca o direito de autodefesa. O membro mais poderoso das Nações Unidas coloca-se acima de sua norma fundamental, a proibição do uso da força (...). Tem-se a imagem de uma potência que usa a sua superioridade militar, tecnológica e econômica para criar de acordo com os conceitos do bem e do mal, portanto de conotação religiosa, uma ordem mundial que também seja conveniente de um ponto de vista geoestratégico. Cria-se assim a alternativa, heuristicamente útil, entre uma constitucionalização progressiva do direito internacional e sua substituição através da ética liberal de uma superpotência ${ }^{18}$.

\section{c) Crítica ao modelo de sociedade mercantil mundial}

Na obra O Ocidente dividido [Suhrkamp, 2004], capítulo 2, Habermas vincula a ética liberal da superpotência à razão neoliberal e seu modelo de sociedade mercantil mundial (concorrência) que conflita com o modelo de sociedade política mundial (bemestar). Esta razão neoliberal inverte a polaridade ao nível das esferas da vida reguladas politicamente e funções de controle do mercado, substituindo o mecanismo regulador da política pelo do mercado. A premissa neoliberal pretende liberar as redes da política governamental das exigências legitimadoras fortes. Isso facilitaria a operacionalização de uma constituição liberal da economia global, cujo objetivo é desregulamentação mundial dos mercados, sem intervencionismo estatal. Mas, se por um lado, a instituição desregulamentada do mercado articula a integração global (econômica), por outro lado, não quer se responsabilizar pelas consequências (políticas). Esta é a crítica de Habermas:

Existe um parentesco entre o programa neoliberal da produção de uma "sociedade do direito privado" em escala mundial e a estrutura organizacional das Multilaterais Econômicas Globais existentes, controladas por governos e ocupadas burocraticamente. A projetada divisão do trabalho entre uma integração da sociedade mundial por meio de mercados liberalizados e a descarga dos demais encargos sociais e ecológicos nos Estados nacionais tornaria supérfluo qualquer tipo de "governo mundial" (global governance). Por este ângulo, a visão de uma política interna mundial deveria ser tida na ponta de um delírio temerário ${ }^{19}$.

Para Habermas, trata-se mais de um projeto de sociedade exportado pelo governo americano a partir de uma teoria da modernização interpretada pelo Consenso de Washington e pela Escola de Chicago que visa substituir o mecanismo regulador da "política" pelo do "mercado". Escreve Habermas: 
O que preocupa realmente é a consequência resultante de uma restruturação neoliberal, no longo prazo, da economia mundial. A política de mudança de polos, que passa do polo das formas políticas de regulamentação para o polo dos mecanismos de mercado, contribui para a perpetuação dela própria à proporção que uma mudança política se torna tanto mais difícil quanto menor for o espaço reservado a intervenções políticas. A autolimitação do espaço de ação política a favor de forças de controle sistêmicas, desejada politicamente, privaria as gerações futuras dos meios indispensáveis para uma eventual correção da rota iniciada ${ }^{20}$.

A redução do espaço de ação política ou a sua substituição pela (des)regulação econômica dificultaria, quando não impediria a avaliação das consequências e a revisão das decisões, implicaria a redução da possibilidade de mudança. A disputa em torno do melhor mecanismo de controle da sociedade expõe uma disputa entre dois modelos de sociedade, a saber: a sociedade mercantil mundial (ou "sociedade da concorrência") $x$ sociedade política mundial (ou "sociedade de bem-estar"). No entanto, nem todas as sociedades estariam inclinadas a assumir as consequências das pretensões neoliberais de uma modernização econômica desregulamentada e que escanteia o espaço do agir político. Escreve Habermas:

\begin{abstract}
Nem todas as nações ocidentais estão dispostas a assumir, para si mesmas e para o mundo, os custos sociais e culturais inerentes à falta de um equilíbrio do bemestar que os neoliberais pretendem impor apoiados no argumento do crescimento acelerado do bem-estar. E por isso aumenta o interesse na manutenção de um certo espaço de ação política em outras culturas que, ao terem acesso ao mercado mundial e ao darem seu assentimento à dinâmica da modernização social, revelam, é bem verdade, a disposição de adaptar e transformar as próprias formas de vida, porém, não a ponto de renunciar a elas substituindo-as por uma forma de vida importada. As múltiplas e variadas faces da sociedade mundial pluralista ou melhor, as múltiplas modernidades - não suportam uma sociedade de mercado mundial politicamente desarmada e totalmente desregulamentada ${ }^{21}$.
\end{abstract}

\title{
d) Neoliberalismo transnacional e déficit democrático das constituições nacionais
}

Como o neoliberalismo transnacional compromete o conteúdo democrático das constituições nacionais? ${ }^{22}$

De modo geral, uma Constituição descreve os papéis a serem desempenhados pela economia (mercado) e pelos cidadãos (sociedade civil) em relação ao poder do Estado; ela esboça a relação dos cidadãos com o Estado, bem como uma ordem jurídica ampla que abarca a totalidade do Estado administrador, economia capitalista e sociedade dos cidadãos; ela é resultado da autoafirmação interna de uma coletividade política que administra a si mesma, e que configura deveres e direitos; ela deposita nos ombros do Estado democrático a responsabilidade de garantir, seja por meios políticos ou jurídicos, a dinâmica econômica e cultural da sociedade. Mesmo quando surgem problemas que remetem para além das tarefas estatais clássicas de integração entre poder estatal, economia e solidariedade dos cidadãos (manter a ordem e garantir a liberdade), o poder organizacional do Estado deve ser capaz de "controlar", política ou juridicamente, as tarefas sociais de legitimação e distribuição. No entanto, observa Habermas, cada vez mais surgem problemas que não se adaptam ou não são resolvíveis pelos meios clássicos da política e do direito (injustiças sociais, riscos e ameaças coletivas, instauração de direitos culturais iguais, dissolução da solidariedade); problemas que colocam em xeque o modo clássico de "controle político" do poder estatal. Escreve Habermas: 
Acompanha a suposição da "controlabilidade política" a construção jurídicoconstitucional de uma sociedade que, por meio das agências estatais, age sobre si mesma conforme a vontade dos seus cidadãos. A substância democrática de uma Constituição, a qual faz dos cidadãos autores das leis às quais eles mesmos, enquanto destinatários, estão submetidos, depende da possibilidade de um tal auto-influenciamento. Somente à proporção que uma sociedade estiver em condições de influenciar a si mesma por meios políticos, a autonomia política dos cidadãos pode adquirir conteúdo. E em nosso contexto tal ponto é decisivo ${ }^{23}$.

O problema é que com a adoção do regime econômico neoliberal globalizado, a "responsabilidade política" operada pelo Estado via meios (políticos e jurídicos) tradicionais de legitimação e integração social é sobrecarregada e levada ao limite. Negociações e contratos transnacionais, privatização de serviços básicos, que antes eram responsabilidade do Estado nacional (segurança pública e penal, comunicações, energia), comprometem o conteúdo democrático da Constituição, despolitizando-a. Independente do controle político (leia-se: de uma coletividade política que administra a si mesma), a dinâmica econômica globalizada adquire dinâmica própria, subtraindo os processos sociais básicos do controle político. Um novo modo de regulamentação é organizado a partir de uma rede de atores e organizações comerciais no nível transnacional, e cujas decisões fogem à influência do Estado nacional. Como consequência, as decisões de novas organizações e instituições supranacionais sobre assuntos são consequentes e interferem diretamente na vida pública dos cidadãos das sociedades nacionais, mesmo que cada vez mais desacopladas dos processos de formação democrática da vontade dos cidadãos de um Estado nacional. Essa falta de ancoragem democrática acentuaria cada vez mais o problema da perda do controle político de uma sociedade sobre si mesma. Para Habermas, esse déficit democrático provocado pelo neoliberalismo globalizado, e que embaraça o sentido clássico de Constituição, poderia ser resolvido apenas numa dimensão também transnacional. Escreve Habermas:

A constelação pós-nacional nos coloca perante uma alternativa desconfortável: ou abandonamos a ideia, pretensiosa, de uma Constituição tida como associação de cidadãos livres e iguais que se administra a si mesma, dando-nos por satisfeitos com uma interpretação sociologicamente desenganada de democracias e Estados de direito, dos quais permanecem apenas as fachadas; ou nós temos de tomar a ideia remanescente da Constituição e dissociá-la do substrato do Estado nacional, revivificando-a, a seguir, na figura pós-nacional de uma sociedade mundial constituída politicamente ${ }^{24}$.

E uma vez que os Estados nacionais são transpassados por redes de informações e negociações transnacionais de uma sociedade econômica mundial, esta sociedade global também deve poder ser integrada pelos mesmos meios do poder, do dinheiro e da solidariedade. Escreve Habermas:

Por que deveria uma Constituição, que ao nível nacional enfrentou com sucesso tais mecanismos de integração lançando mão dos meios da política e do direito, fracassar no nível transnacional ou supranacional? Eu não encontro nenhum argumento de cunho social ou ontológico que obrigue a aceitar a ideia de que a solidariedade de cidadãos de um Estado deva ser confinada em limites nacionais ${ }^{25}$.

\section{e) Fraquezas do liberalismo hegemônico}

Por que uma ordem mundial unipolar não seria recomendável? Qual o déficit normativo do liberalismo hegemônico?

$\mathrm{O}$ comportamento diante da ameaça do terrorismo internacional evidencia o 
quanto o unilateralismo e a supremacia militar mostram-se inadequados para resolver o problema numa sociedade mundial multicultural complexa. Pelo contrário, é preciso uma interligação de serviço secreto, polícia e sistema penal, que se encontram mais facilmente à disposição numa cooperação numa comunidade regulada juridicamente de modo horizontal. A imagem de um mundo unipolar dominado a partir de um centro é inadequada para uma sociedade mundial complexa e descentralizada. Além disso, um governo que quer resolver tudo por conta própria jamais poderá garantir que discerne os seus próprios interesses nacionais daqueles que poderiam ser generalizados e comungados com outros países. Trata-se de uma incapacidade da lógica dos discursos práticos $^{26}$. Por isso, uma justificação ética de um procedimento unilateral que invoca valores da sua própria cultura como supostamente universais não é recomendável por razões normativas. Os conflitos sobre a guerra no Iraque desfazem o discurso normativo da democracia e direitos humanos enquanto retórica vazia. Os norte-americanos teriam promovido o internacionalismo e o multiculturalismo para o resto do mundo, menos para eles mesmos; um unilateralismo hegemônico que se coloca acima do direito internacional.

\section{Críticas, ReFormas e deSAFios das NaÇões UNIDAS}

\section{a) Críticas e reformas}

Em vários momentos de sua obra Habermas demonstra decepção e dirige críticas à Organização das Nações Unidas (ONU). A necessidade de reforma institucional é tematizada nos capítulos 2, 7 e 8 da obra $O$ Ocidente dividido [Suhrkamp, 2004], e no capítulo 9 da obra Ach Europa [Suhrkamp, 2008]. Uma agenda de reformas deveria resultar da avaliação dos sucessos e fracassos das instituições existentes 27.

Na obra $O$ Ocidente dividido [Suhrkamp, 2004], capítulo 7, Habermas fala de sua decepção com a ONU, dirigindo suas críticas às manobras maquiavélicas que dominam a prática das Nações Unidas, à seletividade monstruosa, à precedência desavergonhada de interesses nacionais sobre obrigações globais, ao escudo unilateral, ao desnível de legitimidade entre os Estados-membros (liberais, semiautoritários, despóticos), da capacidade de ação limitada de uma organização mundial que não possui o monopólio da força, da insuficiência de recursos financeiros, da dependência dos governos nacionais e da ausência de contingente militar. Escreve Habermas:

Só se pode aspirar realisticamente à meta ambiciosa de uma política interna mundial sem governo mundial, se a organização mundial (ONU) se restringir a duas funções precípuas - a garantia da paz e a realização global dos direitos humanos - e deixar a coordenação política das áreas como economia, meio ambiente, transportes, saúde, etc., para um nível intermediário de instituições e sistemas de negociação. Mas, por enquanto, esse nível de global players capazes de agir politicamente e de negociar compromissos uns com os outros só é ocupado por algumas instituições, como a organização mundial do comércio. Uma reforma da ONU, ainda que bem-sucedida, não resultaria em nada, se os Estados nacionais, nas diferentes partes do mundo, não se organizarem em regimes continentais conforme o modelo da União Europeia. As iniciativas para isso ainda são modestas. Nisso, não na reforma da $\mathrm{ONU}$, reside o elemento verdadeiramente utópico de um Estado cosmopolita ${ }^{28}$.

Teria se tornado nítido nas últimas décadas o déficit institucional das Nações Unidas, que teria sido irresponsavelmente instrumentalizada. Mesmo que não haja consenso sobre os detalhes da reforma, a ONU precisaria reforçar seu papel de garantir 
e tornar efetivo no âmbito internacional a paz e os direitos humanos elementares, bem como ser menos seletiva na escolha e velocidade no trato com os problemas. Habermas recomenda à ONU ser liberada de um âmbito de problemas como finanças, política econômica, meio ambiente e energia. No sentido da necessidade de organização e regulação, faltam tanto os elementos institucionais como os atores ${ }^{29}$. As atuais redes e organizações políticas existentes são especializadas de modo unilateral. Falta um representativo sistema de negociação transnacional, capaz de ver e ter uma responsabilidade sobre o todo ${ }^{30}$. A questão é saber se os Estados Unidos estariam interessados na União Europeia como parceiro de aliança capaz/apto e independente. Nesse sentido, Habermas sugere a superação da atual mentalidade do "Ocidente dividido" e "bipolaridade do Ocidente". Esta bipolaridade do Ocidente exige da Europa um olhar sobre os Estados Unidos que seja ao mesmo tempo crítico e que resista aos mínimos movimentos de antiamericanismo ${ }^{31}$.

Também no capítulo 8 da obra $O$ Ocidente dividido [Suhrkamp, 20014], Habermas escreve sobre as debilidades e contraexemplos desanimadores da ONU: dependência de recursos financeiros, militares e aprovação da esfera pública (opinião negativa da população) dos Estados-membros, intervenções malsucedidas ou adiadas, obrigações ignoradas, hesitação em intervir militarmente, avaliação seletiva de casos, percepção seletiva e avaliação assimétrica do que seria "catástrofe humanitária", a precedência de interesses nacionais frente às obrigações globais da comunidade internacional ${ }^{32}$, na qual o direito deveria ter precedência. Escreve Habermas:

No plano supranacional, as tarefas constitutivas, que exigem uma margem de decisão mais ampla e um esforço de legitimação maior, ou seja, uma participação dos cidadãos mais solidamente institucionalizada, ficam para trás da imposição do direito $^{33}$.

Na obra Ach Europa [Suhrkamp, 2008], no capítulo 9, também encontramos a crítica sobre a necessidade de reforma das Nações Unidas e da falta de um âmbito institucional e atores.

\section{b) Conquistas das Nações Unidas para constituição política de uma sociedade mundial}

Apesar da crítica à necessidade de reforma, da incapacidade de ação e a falta de eficiência das Nações Unidas, por outro lado, Habermas aponta as conquistas das Nações Unidas no caminho da constituição política de uma sociedade mundial, mostrando em que sentido a Carta das Nações Unidas pode ser interpretada como "constituição da comunidade internacional". Algumas inovações do direito internacional a partir da Carta da ONU seriam passos decisivos em direção à constitucionalização do direito internacional $2^{34}$, criando condições para uma política interna mundial funcionar no plano transnacional. São elas: a associação explícita do objetivo da garantia de paz com uma política dos direitos humanos, a vinculação da proibição do uso da força com uma ameaça realista de persecução penal e de sanções, e o caráter includente da organização mundial e a universalização do direito por ela estabelecido $^{35}$.

Apesar dos conflitos sobre a guerra do Iraque enfraquecerem o discurso normativo dos direitos humanos enquanto retórica vazia, a ONU continua sendo um importante fórum da política mundial. Sanções econômicas, intervenções militares, embargo de armamentos e, especialmente, a recusa do apoio a intervenções militares da OTAN em Kosovo e a entrada de tropas americanas no Iraque (cujo procedimento violava o direito internacional) fortaleceram a reputação política da ONU. Três fatores que sublinham o maior peso político das Nações Unidas: 
O Conselho de Segurança não se engaja apenas em conflitos entre Estados, mas intervém em conflitos dentro dos Estados:

- Seja em reação à violência em situações de guerra civil ou desintegração estatal (como na antiga Iugoslávia, na Libéria, Angola, Burundi, Albânia, República da África Central e Timor-Leste);

- Em reações a violações flagrantes dos direitos humanos e limpezas étnicas (como na Rodésia, África do Sul, norte do Iraque, Somália, Ruanda e Zaire);

- Ou para a instauração de uma ordem democrática (como no Haiti e Serra Leoa $)^{36}$.

Também a instauração de tribunais de crimes de guerra e a discriminação dos Estados que violam os padrões de segurança e direitos humanos nos relatórios de comissões, como a Comissão dos Direitos Humanos e a Anistia Internacional, funcionam como uma materialização da prática do reconhecimento do direito internacional.

\section{c) Limites e desafios}

Apesar de alguns avanços/conquistas/inovações/maior peso político da ONU, falta-lhe, por motivos estruturais, uma base legitimadora para impor, tanto tarefas mais simples como decisões políticas mais consequentes em vista da institucionalização. Por exemplo, faltam elementos institucionais e atores capazes de implementar institucionalmente os direitos humanos ${ }^{37}$. O âmbito dos trabalhos apenas orientadores é muito limitado, de fraca legitimidade ${ }^{38}$.

Além disso, falta ainda o elemento de coesão capaz de criar uma consistência normativa ético-política pós-nacional. Escreve Habermas:

Não vejo nenhum impedimento de ordem estrutural para o prolongamento da solidariedade civil nacional e da política estatal de bem-estar social no âmbito de um Estado federativo pós-nacional. Mas falta à cultura política de uma sociedade mundial a dimensão ético-política comum que seria necessária para uma tal construção de uma comunidade e da identidade globais ${ }^{39}$.

Embora algumas formas de organização internacional não governamentais como a Anistia Internacional ou a Human Rights Watch - pudessem elevar o nível de legitimação tornando mais transparente numa esfera pública os procedimentos decisórios transnacionais, ainda assim permanece um déficit democrático na organização da sociedade mundial. Apesar das inovações no direito internacional a partir da Carta da ONU, falta uma esfera pública mundial forte ${ }^{40}$, falta uma solidariedade civil transnacional, falta uma consciência ampliada de solidariedade cosmopolita $^{41}$, faltam atores capazes de agir transnacionalmente, restando apenas a legitimidade fraca do apelo à solidariedade moral dos direitos humanos que poderia ser compartilhada mundialmente. Escreve Habermas:

Em lugar da solidariedade entre os cidadãos de um Estado, bastaria um consenso negativo, ou seja, um sentimento comum de indignação em relação a belicismos agressivos e violações dos direitos humanos de bandos e governos criminosos ou um sentimento de horror em relação a genocídios e limpezas étnicas ${ }^{42}$.

Estamos todos acostumados a lidar com situações cotidianas em que nos sentimos comprometidos a ser solidários com estranhos, com todos aqueles que possuem um semblante humano. Somente esse universo moral de todas as pessoas responsáveis por suas ações, e que Kant chamou de "reino dos fins", é 
plenamente inclusivo: ninguém é excluído. A injustiça que pode acometer qualquer pessoa, a violação sofrida por não importa qual pessoa, incita nossa sensibilidade moral e provoca em nós uma indignação moral ou uma necessidade de prestar auxílio. Desse sentimento se nutrem os juízos morais, que podem ser racionalmente fundamentados se a adoção recíproca de perspectivas levar a uma percepção suficientemente descentralizada do conflito e à consideração igual de todos os interesses em questão $0^{43}$.

Por fim, no prefácio da obra Sobre a Constituição da Europa [Suhrkamp, 2011], Habermas alerta que, embora as experiências da violação dos direitos humanos tenham provocado reações de indignação no nível mundial nas últimas décadas, a pretensão cosmopolita dos direitos humanos não pode se esgotar nesse sentimento moral de indignação diante de relações injustas de uma sociedade altamente desigual, mas seria preciso que os direitos humanos fossem incorporados institucionalmente em uma sociedade constituída politicamente44. Mas este é o limite (deficit) para o aprofundamento democrático das instituições transnacionais existentes, tais como a ONU. Como já observava Habermas no capítulo 2 da obra Era das transições [Suhrkamp, 2001], a institucionalização dos direitos humanos permanece fraca no nível global, pois não há instâncias jurídicas efetivas, reconhecidas e capazes de aplicação e imposição. A "subinstitucionalização" do direito dos cidadãos do mundo (direitos humanos) expressa-se na lacuna que existe entre legitimação e efetividade das intervenções [da ONU]45.

\section{REFERÊNCIAS}

BRUNKHORST, Hauke. Legitimationskrisen: Verfassungsprobleme der Welgeselschaft. BadenBaden: Nomos, 2012. (Ed.). Demokratie in der Weltgeselschaft. Baden-Baden: Nomos, 2009.

HABERMAS, Jürgen. Im Sog der Technokratie. Berlin: Suhrkamp, 2013. Zur Verfassung Europas: Ein Essay. Berlin: Suhrkamp, 2011. . Ach Europa: Kleinen Politischen Schriften. Frankfurt: Suhrkamp, 2008. Zwischen Naturalismus und Religion. Frankfurt: Suhrkamp, 2005. Der gespaltene Westen. Frankfurt: Suhrkamp, 2004. Zeit der Übergänge. Frankfurt: Suhrkamp, 2001. Die postnationale Konstellation. Frankfurt: Suhrkamp, 1998

LUBENOW, Jorge A. O Ocidente dividido: o impacto da globalização econômica neoliberal na integração política da União Europeia. Aufklärung: Revista de Filosofia, v.4, n.3, p. 119134, 2017.

. A redefinição do perfil político da Europa de estatal-social para econômico-liberal: uma análise crítica a partir de Jürgen Habermas. Aufklärung: Revista de Filosofia, v.3, n.2, p. 95-112, 2016.

. The paradox of technocratic democracy and the democratic deficit of european institutions by Jürgen Habermas. Aufklärung: Revista de Filosofia, v.2, n.2, p. 103-122, 2015.

Hauke Brunkhorst e o conceito de solidariedade democrática como crítica à esfera pública pós-nacional de Jürgen Habermas. Veritas: Revista de Filosofia (PUC-RS), v. 58, n.1, p. 118-130, 2013.

. \& da SILVA, Bartolomeu L. Esfera pública 50 anos depois. Dossiê Revista Problemata, v.3, 2012.

. \& da SILVA, Bartolomeu L. AZEVEDO, Edmilson A. de. Habermas 80 anos. Rio de Janeiro: Tempo Brasileiro, 2010, 2v. 


\section{Notas}

1 HABERMAS, Jürgen. Zeit der Übergänge. Frankfurt: Suhrkamp, 2001, cap. 2, p. 28.

2 HABERMAS, Jürgen. Der gespaltene Westen. Frankfurt: Suhrkamp, 2004, Vorwort, p. 7.

3 HABERMAS, Der gespaltene Westen, cap. 2, p. 38.

4 HABERMAS, Der gespaltene Westen, cap. 2, p. 59.

5 HABERMAS, Der gespaltene Westen, cap. 2, p. 66.

6 HABERMAS, Der gespaltene Westen, cap. 7, p. 85.

7 Cf. HABERMAS, Der gespaltene Westen, cap. 7, p. 94.

8 HABERMAS, Der gespaltene Westen, cap. 7, p. 101-102.

9 HABERMAS, Jürgen. Ach Europa. Frankfurt: Suhrkamp, 2008, cap. 9.

10 HABERMAS, Ach Europa, cap. 9, p. 117. Aqui Habermas alerta ser necessário cuidar para que o antiamericanismo não se transforme em ódio contra o Ocidente e, nesse sentido, seria importante na Europa um front contra a política do governo americano, pois não se pode confundir antiamericanismo com o sentimento antimoderno contra o mundo ocidental.

11 HABERMAS, Der gespaltene Westen, cap. 8, p. 179-180.

12 HABERMAS, Der gespaltene Westen, cap. 8, p. 180-181.

13 HABERMAS, Der gespaltene Westen, cap. 7, p. 108.

14 HABERMAS, Der gespaltene Westen, cap. 8, p. 178.

15 HABERMAS, Der gespaltene Westen, cap. 8, p. 160.

16 Em nota Habermas agradece ao Professor Hauke Brunkhorst pelas contribuições estimulantes durante a preparação do seu texto. Das obras de Brunkhorst, ver: Legitimationskrisen: Verfassungsprobleme der Welgeselschaft. Baden-Baden: Nomos, 2012; Demokratie in der Weltgeselschaft. Baden-Baden: Nomos, 2009.

17 HABERMAS, Der gespaltene Westen, cap. 8, p. 182-183.

18 HABERMAS, Der gespaltene Westen, cap. 8, p. 146.

19 HABERMAS, Jürgen. Zwischen Naturalismus und Religion. Frankfurt: Suhrlamp, 2005, cap. 11, p. 364.

20 HABERMAS, Zwischen Naturalismus und Religion, cap. 11, p. 364.

21 HABERMAS, Zwischen Naturalismus und Religion, cap. 11, p. 365.

22 Sobre os problemas da integração política europeia e o novo perfil econômico-liberal da Europa, ver: LUBENOW, O Ocidente dividido: o impacto da globalização econômica neoliberal na integração política da União Europeia. Aufklärung: Revista de Filosofia, v.4, n.3, p. 119-134, 2017; LUBENOW, A redefinição do perfil político da Europa de estatalsocial para econômico-liberal: uma análise crítica a partir de Jürgen Habermas. Aufklärung: Revista de Filosofia, v.3, n.2, p. 95-112, 2016.

23 HABERMAS, Zwischen Naturalismus und Religion, cap. 11, p. 343-344.

24 HABERMAS, Zwischen Naturalismus und Religion, cap. 11, p. 345.

25 HABERMAS, Zwischen Naturalismus und Religion, cap. 11, p. 346.

26 CF. HABERMAS, Der gespaltene Westen, cap. 8, p. 183.

27 Cf. HABERMAS, Der gespaltene Westen, cap. 8, p. 172-173.

28 HABERMAS, Der gespaltene Westen, cap. 7, p. 107.

29 Esta crítica também é retomada na obra Ach Europa, cap. 9.

30 Cf. HABERMAS, Ach Europa, cap. 9, p. 121.

31 Cf. HABERMAS, Ach Europa, cap. 9, p. 122.

32 Cf. HABERMAS, Der gespaltene Westen, cap. 8, p. 169-170.

33 HABERMAS, Der gespaltene Westen, cap. 8, p. 173.

34 Cf. HABERMAS, Der gespaltene Westen, cap. 8, p. 160.

35 HABERMAS, Der gespaltene Westen, cap. 8, p. 159.

36 Cf. HABERMAS, Der gespaltene Westen, cap. 8, p. 168.

37 Cf. HABERMAS, Der gespaltene Westen, cap. 2, 7 e 8; Ach Europa, cap. 9.

38 HABERMAS, Jürgen. Die postnationale Konstellation. Frankfurt: Suhrkamp, 1998, cap. 4.

39 HABERMAS, Die postnationale Konstellation, cap. 4, p. 163. Para Habermas, o recurso ao patriotismo constitucional nacional dos defensores de uma política interna mundial não é 
satisfatório e, nesse sentido, é preciso encontrar um outro caminho: "Uma comunidade cosmopolita de cidadãos do mundo não oferece, portanto, nenhuma base suficiente para uma política interna mundial. A institucionalização de procedimentos de votação de interesses, de universalização dos mesmos e de construção engenhosa desses interesses em comum não se pode consumar na estrutura organizacional de um Estado mundial. Projetos para uma democracia cosmopolita precisam se orientar por outro modelo" (HABERMAS, Die postnationale Konstellation, cap. 4, p. 163-164).

40 Sobre os discursos críticos, ver: LUBENOW, Hauke Brunkhorst e o conceito de solidariedade democrática como crítica à esfera pública pós-nacional de Jürgen Habermas. Veritas: Revista de Filosofia (PUC-RS), v. 58, n.1, p. 118-130, 2013; LUBENOW, A categoria de esfera pública em Jürgen Habermas. 2.ed. Curitiba: CRV, 2015; e as coletâneas: LUBENOW; SILVA; AZEVEDO, Habermas 80 anos. Rio de Janeiro: Tempo Brasileiro, 2010, 2v; LUBENOW; SILVA. Esfera pública 50 anos depois. Dossiê Revista Problemata, v.3, 2012.

41 Cf. HABERMAS, Die postnationale Konstellation, cap. 4, p. 168.

42 HABERMAS, Der gespaltene Westen, cap. 7, p. 107-108.

43 HABERMAS, Jürgen. Zur Verfassung Europas. Berlin: Suhrkamp, 2011, cap. 2, p. 91. Nesse ponto, Pinzani destaca uma mudança importante na fundamentação habermasiana da teoria democrática e justa de uma sociedade global, na qual a teoria do discurso teria sido substituída por uma ideia transcendente de justiça que aguarda sua realização jurídica e é justificada agora por razões morais (o apelo à dignidade de cada um que se impõe como uma força superior a qualquer outro tipo de argumento), e que aproximaria Habermas daqueles defensores das teorias normativas da justiça que antes eram rechaçadas. $\mathrm{Cf}$. PINZANI, "Apresentação à edição brasileira". In: Jürgen Habermas: sobre a Constituição da Europa. São Paulo: Ed. UNESP, 2012, p. XXX. No entanto, diferente de Pinzani, penso que o recurso aos direitos humanos apenas fornece uma alternativa normativa dada a ausência de uma esfera pública e solidariedade civil transnacional forte. Nesse sentido, o deslocamento na fundamentação da filosofia política não significaria tanto um deslocamento para uma teoria mais transcendente de justiça, como acredita Pinzani, mas apenas o último recurso jurídico para tentar salvar uma concepção constitucional de democracia, mas que conceitualmente não abre mão da esfera pública e sociedade civil. Habermas não abandonou a concepção discursiva da democracia, do direito e do Estado de direito, mas apenas deslocou a discussão para os problemas da unificação política europeia e da juridificação das relações internacionais. (Cf. HABERMAS, Im Sog der Technokratie, Berlin: Suhrkamp, 2013, cap. 4, p. 72). Outra pesquisa poderia elucidar melhor o significado deste apelo moral de Habermas aos direitos humanos como fundamento filosófico da teoria transnacional da democracia, não tanto em termos de teoria discursiva (como fez Pinzani), mas da teoria da democracia (como isso afeta a conexão interna entre soberania popular e direitos humanos, a tese da co-originariedade entre autonomia privada e autonomia pública e a relação entre legitimidade e legalidade?) e da teoria crítica (a ênfase nos direitos humanos é uma guinada para o indivíduo, uma orientação mais individualista? Nos moldes de Adorno, que abriu mão da crítica social ampla em favor de uma crítica a partir do indivíduo/consciência? Significa uma aproximação da noção de reconhecimento e um afastamento da noção de redistribuição como fez Honneth? Ou como Rainer Forst, que tem um capítulo "A teoria crítica dos direitos humanos" na obra Contextos da justiça?

44 Cf. HABERMAS, Zur Verfassung Europas, Vorwort, p. 11.

45 Cf. HABERMAS, Jürgen Zeit der Übergänge. Frankfurt: Suhrkamp, 2001, cap. 2, p. 34-35. 